\title{
Relationship between Creep Property and Loading-Rate Dependence of Strength of Artificial Methane-Hydrate-Bearing Toyoura Sand under Triaxial Compression
}

\author{
Kuniyuki Miyazaki ${ }^{1, *}$, Norio Tenma ${ }^{2}$ and Tsutomu Yamaguchi ${ }^{3}$ \\ 1 Institute for Geo-Resources and Environment, National Institute of Advanced Industrial Science and \\ Technology, Tsukuba 305-8567, Japan \\ 2 Research Institute of Energy Frontier, National Institute of Advanced Industrial Science and Technology, \\ Tsukuba 305-8569, Japan; tenma-n@aist.go.jp \\ 3 Department of Environmental Science, Toho University, Funabashi 274-8510, Japan; \\ yamaguchi@env.sci.toho-u.ac.jp \\ * Correspondence: miyazaki-kuniyuki@aist.go.jp; Tel.: +81-29-861-8753
}

Received: 18 July 2017; Accepted: 21 September 2017; Published: 22 September 2017

\begin{abstract}
Methane hydrate is anticipated to be a promising energy resource. It is essential to consider the mechanical properties of a methane hydrate reservoir to ensure sustainable production, since its mechanical behavior may affect the integrity of the production well, the occurrence of geohazards, and gas productivity. In particular, the creep property of methane-hydrate-bearing sediment is thought to have great significance in the long-term prediction of the mechanical behaviors of a reservoir. In earlier studies, triaxial compression tests were conducted on artificial methane-hydrate-bearing Toyoura sand under three axial-loading conditions, i.e., constant-strain-rate test, constant-stress-rate test, and creep (constant-stress) test. In this paper, the time-dependent properties of the methane-hydrate-bearing Toyoura sand observed in these tests were quantitatively discussed and found to be almost in agreement. The creep life obtained from the creep tests had a reasonably strong correlation with the loading-rate dependencies of strength, obtained from the constant-strain-rate tests and constant-stress-rate tests based on a simple hypothesis. The findings are expected to be used to develop a constitutive model considering the time-dependent behaviors of hydrate-bearing soil in future studies, and to improve the reliability of long-term prediction of the geomechanical response to gas extraction from a reservoir.
\end{abstract}

Keywords: methane hydrate; sand; triaxial compression; creep; loading rate

\section{Introduction}

Methane hydrate consists of cagelike crystal structures made up of hydrogen-bonded water molecules surrounding a guest molecule of methane. Because vast amounts of natural methane hydrate exist in marine sediment worldwide and in permafrost regions, methane hydrate is anticipated to be a promising energy resource [1-4].

The prediction of the geomechanical response to gas extraction from a reservoir is an important research issue for the sustainable production of methane hydrate since the mechanical behaviors of a methane hydrate reservoir may affect the integrity of the production well, the occurrence of geohazards, and gas productivity [5-8]. Some simulation studies concerning the mechanical behaviors of a methane hydrate reservoir have been reported. Rutqvist et al. [9] analyzed the geomechanical response during depressurization production from hydrate-bearing permafrost deposits. Kimoto et al. [10] analyzed the seabed ground deformation induced by methane hydrate production. Klar et al. [11] analyzed 
the mechanical behavior of horizontal wells in hydrate-bearing sediments during methane hydrate extraction. Such simulations require constitutive models for hydrate-bearing sediments.

A constitutive model should be developed on the basis of experimentally obtained mechanical properties. An experimental method for performing triaxial compression tests on artificial methanehydrate-bearing sediment samples has been developed [12], and the mechanical properties of methanehydrate-bearing sediments have been partially clarified [13-24]. However, the time-dependent behaviors of methane-hydrate-bearing sediments have not been fully clarified, although they are thought to have great significance in predicting the long-term behaviors of sediment over a time scale of decades. Thus, few models consider the time-dependent behaviors of methane-hydrate-bearing sediments appropriately based on experimentally obtained properties [25-27], although many constitutive models for methane-hydrate-bearing sediments have been proposed in earlier works [10,11,28-30].

One of the methods of investigating the time-dependent behavior of a geomaterial is to measure the loading-rate dependence of its mechanical properties. Miyazaki et al. $[18,21,23,24]$ found that the axial-strain-rate dependence of methane-hydrate-bearing sand is as strong as that of frozen sand, and is stronger than that of water-saturated sand and many other geomaterials. This finding suggests that the time-dependence of methane-hydrate-bearing sediment is significantly strong for a geomaterial. Creep is also a time-dependent behavior and is thought to be closely related to the loading-rate dependence of mechanical properties. However, the creep property of methane-hydrate-bearing sediment has not been clarified sufficiently $[21,22,24]$.

This study aims to provide organized basic data concerning the time-dependent properties of methane-hydrate-bearing Toyoura sand, and to search for quantitative relationships between the loading-rate dependencies and the creep property [18,21-23]. In this paper, the methods and results of three types of triaxial compression tests conducted on artificial methane-hydrate-bearing Toyoura sand are first presented: constant-strain-rate test, constant-stress-rate test, and creep (constant-stress) test. The experimental procedure developed by Masui et al. [12] was generally followed in the tests. Based on the review of the test results, the time-dependent behaviors observed in the tests were quantitatively compared and the relationship between them is discussed. Moreover, some constitutive models presented in earlier works are reviewed from that viewpoint.

\section{Testing Method}

The testing method used in earlier works $[12,18,21-23]$ is described in this section.

\subsection{Specimen Preparation}

The specimens were prepared by freezing cylindrical unsaturated sand specimens consisting of Toyoura sand (average particle size: $0.230 \mathrm{~mm}$, uniformity coefficient: 1.38 , fine fraction content: $0 \%$ ). The water saturation was adjusted to 0.60 . The average porosity of the host specimens was $38 \%$. The dry density calculated using the weight of sand used and the size of each host specimen was $1.68 \mathrm{~g} / \mathrm{cm}^{3}$ on average, corresponding to a relative density of $96 \%$, indicating that the sand particles in the host specimens were well compacted. Each host specimen was $50 \mathrm{~mm}$ in diameter and $100 \mathrm{~mm}$ in length.

The testing apparatus used for synthesizing methane hydrate in the host specimens, as well as for axial loading under triaxial compression, is drawn schematically in Figure 1. Refer to Miyazaki et al. [19] for the specifications and the system employed in the apparatus. Methane hydrate was synthesized in the pore space of the specimen by the following procedure. First, a frozen host specimen was set in the triaxial cell. Then, a cell pressure of $1 \mathrm{MPa}$ was applied, and methane supplied from a methane gas cylinder was percolated through the specimen from its lower end, replacing the pore air, at a temperature of $268 \mathrm{~K}$ or less. The methane gas pressure was increased to $8 \mathrm{MPa}$ at a rate of approximately $0.7 \mathrm{MPa} / \mathrm{min}$, while the cell pressure was increased to $9 \mathrm{MPa}$ at the same rate to maintain the effective confining pressure at $1 \mathrm{MPa}$. Then, the temperature inside the triaxial cell was raised to $278 \mathrm{~K}$. The cell pressure, pore gas pressure, and temperature were then kept constant for $24 \mathrm{~h}$ 
in order to form methane hydrate in the pore space of the host specimen. After that, water was injected into the specimen to replace the gaseous methane remaining in its pore space. The cell pressure, pore pressure, and temperature were kept constant during the water substitution process. Over $4 \times 10^{-4} \mathrm{~m}^{3}$ of water passed through the specimen during the water substitution process. We hereafter refer to a water-saturated specimen of the densely packed sand sediment containing synthesized methane hydrate prepared by the above procedure as a hydrate-sand specimen.

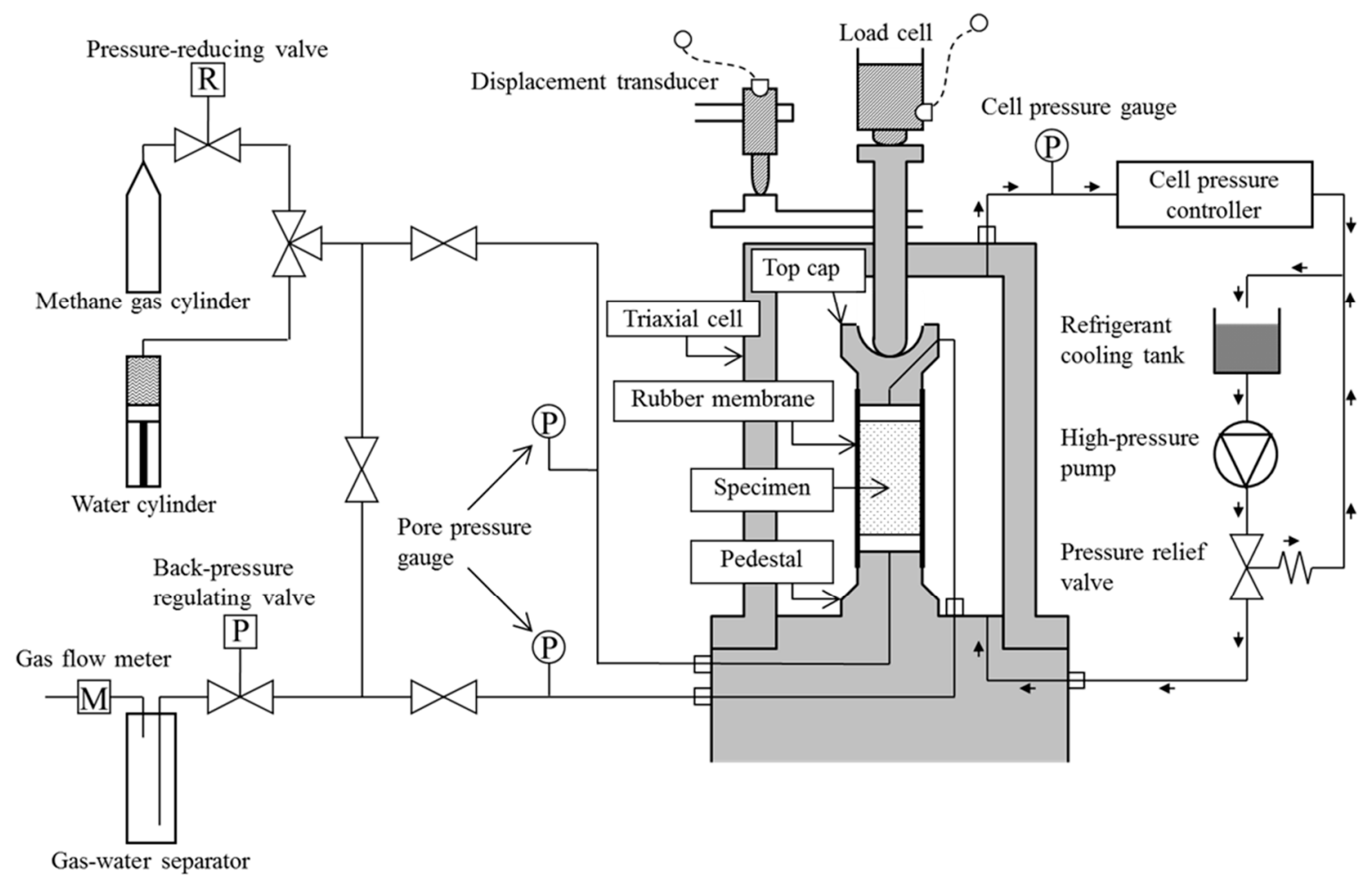

Figure 1. Schematic illustration of testing apparatus.

\subsection{Axial Loading}

Axial loading was conducted on all specimens while maintaining the pore pressure at $8 \mathrm{MPa}$ (drained condition), the confining pressure at $9 \mathrm{MPa}$, and the temperature at $278 \mathrm{~K}$. Thus, the effective confining pressure was continuously maintained at $1 \mathrm{MPa}$. Since the conditions of pore pressure and temperature are within the methane hydrate stability zone, the effect on the mechanical properties of the methane hydrate dissociation during axial loading is thought to be negligibly small. Results of three types of axial-loading tests are presented in this paper: constant-strain-rate test, constant-stress-rate test, and creep (constant-stress) test, the conditions of which are shown in Tables 1-3, respectively. The axial strain $\varepsilon_{a}$ was calculated by dividing the axial displacement, measured with two $25 \mathrm{~mm}$ linear variable differential transformers (LVDTs), by the initial height of the specimen. In this paper, a positive strain value denotes compression. In the constant-strain-rate tests, the axial strain $\varepsilon_{a}$ was increased at a rate $C_{e}$ ranging from 0.001 to $0.1 \% / \mathrm{min}$. In the constant-stress-rate tests, the differential stress $\Delta \sigma\left(=\sigma_{a}-\sigma_{r}\right)$ was increased at a rate $C_{s}$ ranging from 0.01 to $1 \mathrm{MPa} / \mathrm{min}$, where $\sigma_{a}$ and $\sigma_{r}$ are the axial and radial stresses, respectively. In the creep tests, the differential stress $\Delta \sigma$ was increased to a predetermined creep stress $\sigma_{c r}$. In this paper, constant-strain-rate and constant-stress-rate tests are inclusively referred to as constant-loading-rate tests.

After axial loading, the methane hydrate in the specimen was dissociated by reducing the pore pressure. The initial volume of methane hydrate formed in the specimen, and thus the methane hydrate saturation $S_{h}$ of the specimen, was calculated from the volume of released methane measured 
by a gas flow meter. The $S_{h}$ for each specimen used in the constant-strain-rate tests, constant-stress-rate tests, and creep tests are also shown in Tables $1-3$, respectively.

Table 1. Conditions of constant-strain-rate tests.

\begin{tabular}{cc}
\hline Axial-Strain Rate $C_{\boldsymbol{e}}$ & Methane Hydrate Saturation $S_{\boldsymbol{h}}$ \\
\hline $0.1 \% / \mathrm{min}$ & $39 \%, 40 \%, 41 \%, 41 \%(15 \%, 16 \%, 21 \%, 31 \%, 34 \%, 35 \%, 48 \%) *$ \\
$0.05 \% / \mathrm{min}$ & $37 \%, 37 \%, 45 \%$ \\
$0.01 \% / \mathrm{min}$ & $43 \%, 43 \%$ \\
$0.005 \% / \mathrm{min}$ & $43 \%$ \\
$0.001 \% / \mathrm{min}$ & $42 \%, 41 \%$ \\
\hline & $* S_{h}$ values in parentheses were used to derive Equation (1)
\end{tabular}

Table 2. Conditions of constant-stress-rate tests.

\begin{tabular}{cc}
\hline Differential-Stress Rate $\boldsymbol{C}_{\boldsymbol{s}}$ & Methane Hydrate Saturation $\boldsymbol{S}_{\boldsymbol{h}}$ \\
\hline $1 \mathrm{MPa} / \mathrm{min}$ & $39 \%, 42 \%, 42 \%$ \\
$0.1 \mathrm{MPa} / \mathrm{min}$ & $44 \%, 50 \%$ \\
$0.01 \mathrm{MPa} / \mathrm{min}$ & $44 \%, 48 \%, 50 \%$ \\
\hline
\end{tabular}

Table 3. Conditions of creep tests.

\begin{tabular}{cc}
\hline Creep Stress $\sigma_{c r}$ & Methane Hydrate Saturation $S_{h}$ \\
\hline $1 \mathrm{MPa}$ & $42 \% *, 42 \% *$ \\
$2 \mathrm{MPa}$ & $48 \% *, 48 \% *$ \\
$3 \mathrm{MPa}$ & $40 \% *, 45 \% *, 47 \% *$ \\
$4 \mathrm{MPa}$ & $39 \% *, 50 \% *$ \\
$4.5 \mathrm{MPa}$ & $41 \%, 42 \%, 42 \% *$ \\
$5 \mathrm{MPa}$ & $36 \%, 41 \%, 45 \%, 48 \%$ \\
$5.5 \mathrm{MPa}$ & $36 \%, 39 \%, 48 \%$ \\
\hline
\end{tabular}

* The specimens indicated by asterisks did not exhibit final rupture.

\section{Review of Test Results}

\subsection{Constant-Loading-Rate Tests}

In the constant-strain-rate test, the differential stress $\Delta \sigma$ increases and the slope of the curve decreases until $\Delta \sigma$ reaches a peak, then $\Delta \sigma$ gradually decreases with the axial strain $\varepsilon_{a}$ as shown in Figure 2. Masui et al. [12] noted that the strength (maximum differential stress) $\sigma_{f e}$ increases with the methane hydrate saturation $S_{h}$ due to the cementation effect of hydrate between sand particles. Miyazaki et al. [27] obtained the following approximate formula by least-squares regression:

$$
\sigma_{f e 0.1}=\sigma_{f e 0}+42.2 \times S_{h}^{3.24},
$$

where $\sigma_{f e 0.1}$ is a function of $S_{h}$ expressing the strength at an axial-strain rate $C_{e}$ of $0.1 \% / \mathrm{min}$, and $\sigma_{f e 0}$ is $3.75 \mathrm{MPa}$, which is the average strength of the sand specimens. Note that some values of $S_{h}$ in Table 1 are in parentheses; Miyazaki et al. [27] used these results to derive Equation (1).

The $\Delta \sigma-\varepsilon_{a}$ curve for the hydrate-sand specimens depends on $C_{e}[18,21,23,24]$. Figure 3 clearly shows that, as $C_{e}$ increases, the strength $\sigma_{f e}$ increases and the axial strain at the peak strength $\varepsilon_{f e}$ decreases. As noted by Miyazaki et al. [18], the time-dependence of a hydrate-sand specimen is stronger than that of a non-hydrate-sand specimen, because the axial-strain-rate dependence of the mechanical properties of the non-hydrate-sand specimens was hardly observed. Miyazaki et al. [18] also reported that the time-dependence of a hydrate-sand specimen is as strong as that of frozen 
sand and is stronger than those of most geomaterials such as rocks and soils. Parameswaran [31] presumed that the strain-rate dependence of frozen sand is governed by the liquid phase around the sand grains-namely, a quasi-liquid layer-and that this phase is associated with the melting of ice under pressure at the points where grains are in contact. Miyazaki et al. [18] suggested that the strong time-dependence of hydrate-sand specimens was caused by the local dissociation of hydrate occurring at the points where hydrate grains are in contact, similar to the pressure melting of ice.

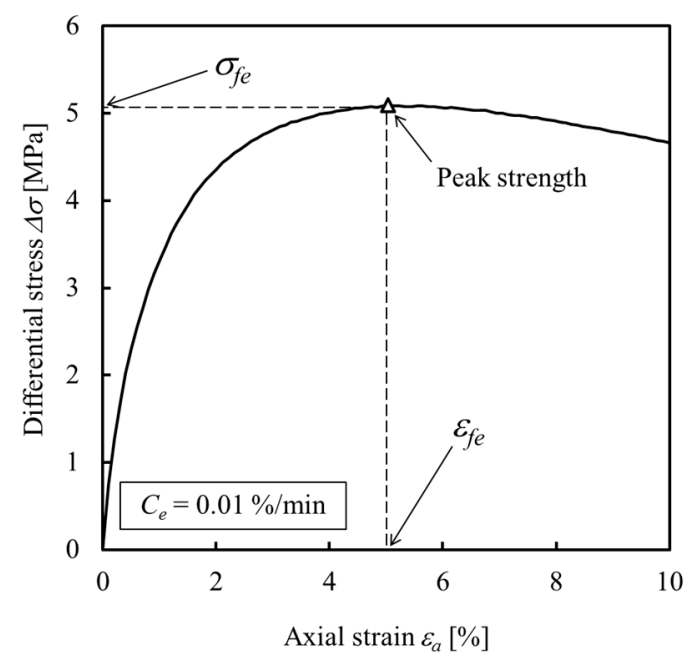

Figure 2. Differential stress $\Delta \sigma$ versus axial strain $\varepsilon_{a}$ in constant-strain-rate test $[18,21]$.

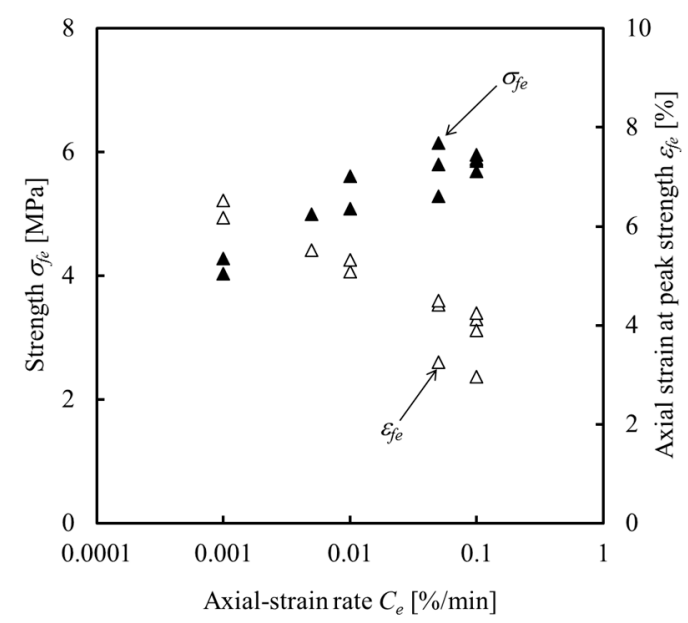

Figure 3. Strength $\sigma_{f e}$ and axial strain at the peak strength $\varepsilon_{f e}$ versus axial-strain rate $C_{e}$ in constant-strain-rate tests $[18,21]$.

In the constant-stress-rate test, the differential stress $\Delta \sigma$ increases and the slope of the curve decreases until final rupture of the hydrate-sand specimen occurs as shown in Figure 4 [26]. The $\Delta \sigma-\varepsilon_{a}$ curve for the hydrate-sand specimens depends on the differential-stress rate $C_{s}$. Figure 5 shows that, as $C_{s}$ increases, the strength (differential stress at the final rupture) $\sigma_{f_{s}}$ increases and the axial strain at the final rupture $\varepsilon_{f_{s}}$ decreases [22]. 


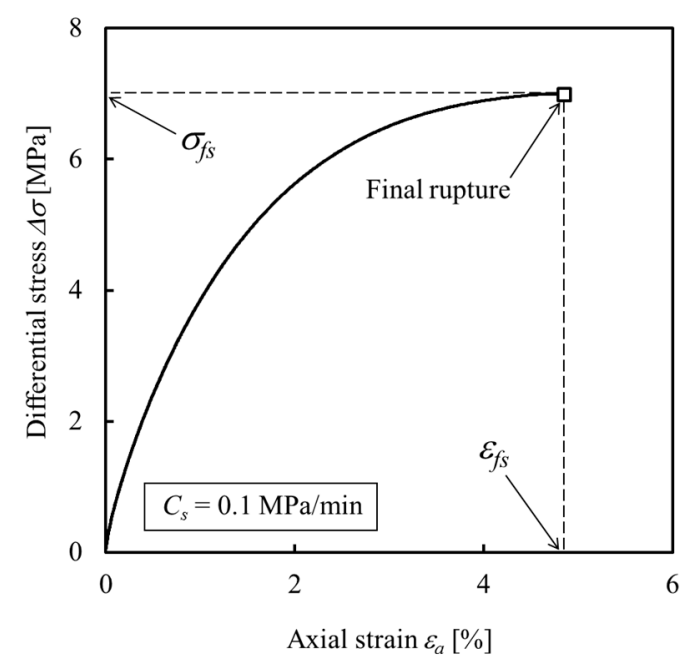

Figure 4. Differential stress $\Delta \sigma$ versus axial strain $\varepsilon_{a}$ in constant-stress-rate test [26].

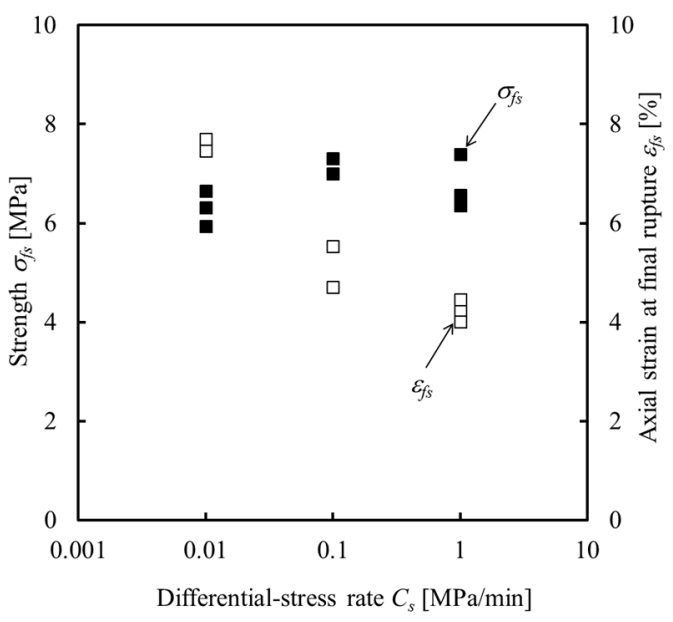

Figure 5. Strength $\sigma_{f_{s}}$ and axial strain at the final rupture $\varepsilon_{f_{s}}$ versus differential-stress rate $C_{s}$ in constant-stress-rate tests [22].

\subsection{Creep Tests}

In the creep tests, $\Delta \sigma$ was increased to $\sigma_{c r}$. We designate the point when $\Delta \sigma$ reaches $\sigma_{c r}$ as the starting point of creep. We hereafter refer to an increase in $\varepsilon_{a}$ from the starting point of creep and the temporal derivative of $\varepsilon_{a}$ as the creep strain $\varepsilon_{c r}$ and creep-strain rate $\left(d_{c r} / d t\right)$, respectively. The relationship between creep strain $\varepsilon_{c r}$ and elapsed time $t$ for the hydrate-sand specimen with $S_{h}=41 \%$ and $\sigma_{c r}=4.5 \mathrm{MPa}$ is shown in Figure 6 [22,24]. The creep strain $\varepsilon_{c r}$ monotonically increased with the elapsed time $t$, while $\left(d \varepsilon_{c r} / d t\right)$, i.e., the slope of the $\varepsilon_{c r}-t$ curve, changed with $t$ as follows: first, $\left(d \varepsilon_{c r} / d t\right)$ decreased; second, it remained almost constant; and third, it increased. These three phases of creep are often referred to as primary creep, secondary creep, and tertiary creep, respectively. During secondary creep, $\left(d \varepsilon_{c r} / d t\right)$ did not remain exactly constant; it reached a minimum at a point during secondary creep, as indicated with a triangle in Figure 6. At the end of tertiary creep, as indicated with a square in Figure 6, the specimen could not withstand the creep stress $\sigma_{c r}$ and finally ruptured. Note that not all the hydrate-sand specimens exhibited final rupture before 200,000 s had elapsed, as shown in Table 3. 


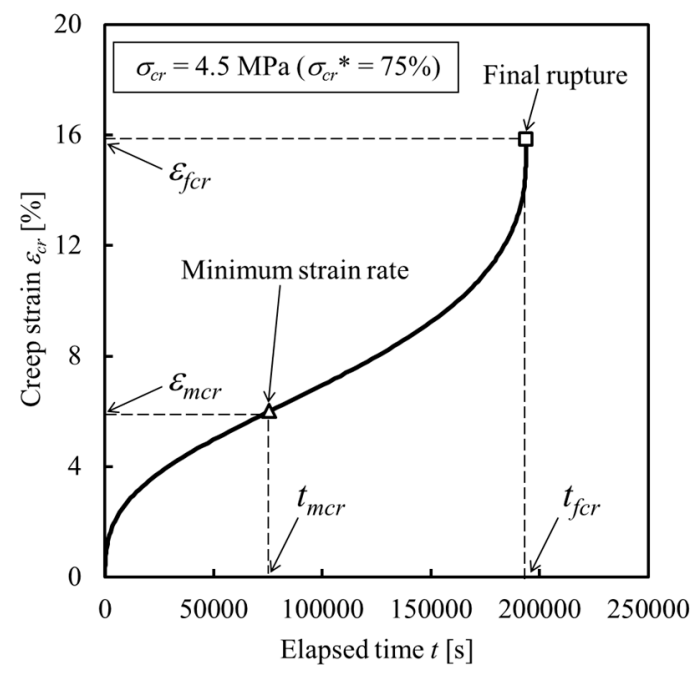

Figure 6. Creep strain $\varepsilon_{c r}$ versus elapsed time $t$ [22,24].

The normalized creep stress $\sigma_{c r}{ }^{*}$, which is the ratio of creep stress to the strength $\sigma_{f e 0.1}$, is often useful in comparing creep properties between geomaterials with different strengths. In this paper, since each specimen has a different value of $S_{h}$, we decided to calculate $\sigma_{c r}{ }^{*}$ using the following equation:

$$
\sigma_{c r}{ }^{*}=\sigma_{c r} / \sigma_{f e 0.1}
$$

According to Equation (1), which was derived from the results of constant-strain-rate tests at $C_{e}=0.1 \% / \mathrm{min}, \sigma_{f e 0.1}$ depends on $S_{h}$. For example, as represented in Figure 6, $\sigma_{c r}$ of $4.5 \mathrm{MPa}$ for the hydrate-sand specimen with $S_{h}=41 \%$ corresponds to $\sigma_{c r}{ }^{*}=75 \%$. Miyazaki et al. [22,24] noted that $\varepsilon_{c r}$ of the hydrate-sand specimen is larger than that of the non-hydrate-sand specimen at nearly equal $\sigma_{c r}{ }^{*}$, suggesting that the time-dependence of a hydrate-sand specimen is stronger than that of a non-hydrate-sand specimen as described above.

Figure 7 shows $\left(d \varepsilon_{c r} / d t\right)$ plotted against $t$ for the test result shown in Figure 6. The $\left(d \varepsilon_{c r} / d t\right)$ decreased with $t$ during primary creep, reached a minimum during secondary creep, and then increased with $t$ during tertiary creep. As shown in earlier works $[22,24,26,27]$, the slope of the $\log \left(d \varepsilon_{c r} / d t\right)-\log (t)$ relationship in primary creep varied with $\sigma_{c r}$ in the range of -1 to -0.4 ; the slope approached -1 as $\sigma_{c r}$ decreased. Hereafter, $m$ is the slope of the $\log \left(d \varepsilon_{c r} / d t\right)-\log (t)$ relationship in primary creep.

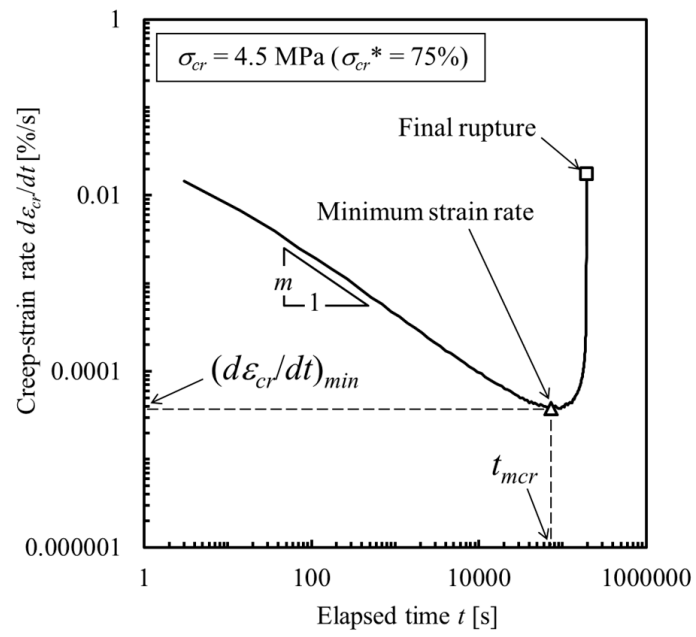

Figure 7. Creep-strain rate $\left(d \varepsilon_{c r} / d t\right)$ versus elapsed time $t[22,24,26,27]$. 
There have been some experimental studies on the primary creep behavior of frozen sand. Ting and Martin [32] and Ting [33] showed that $m$ ranged from -0.8 to -0.6 for frozen Manchester fine sand under uniaxial compression. Sales [34] reported that $m$ decreased and approached -1 as $\sigma_{c r}$ decreased for both frozen Ottawa sand and frozen Manchester fine sand under triaxial compression. In this sense, the primary creep behavior of hydrate-sand specimens closely resembles that of frozen sand. However, Sales \& Haines [35] reported that $m$ for Hanover silt and Suffield clay ranged from -1.1 to -0.9 and was nearly independent of $\sigma_{c r}$. It was reported that $m$ is nearly equal to -1 for unfrozen sand [36], in agreement with our result for non-hydrate-sand specimens [22,24]. For reference, it is also reported that $m$ is nearly equal to -1 for many types of rocks $[37,38]$.

Some hydrate-sand specimens exhibited tertiary creep and some exhibited final rupture. The elapsed time until the creep-strain rate reached a minimum is hereafter expressed as $t_{m c r}$. The elapsed time until final rupture is hereafter referred to as the creep life $t_{f c r}$. Figure 8 shows that the minimum creep-strain rate $\left(d \varepsilon_{c r} / d t\right)_{\min }$ decreases with increasing $t_{m c r}$ and $t_{f c r}$, with a linear relationship between $\log \left(\left(d \varepsilon_{c r} / d t\right)_{\min }\right)$ and both $\log \left(t_{m c r}\right)$ and $\log \left(t_{f c r}\right)$, and a slope of approximately -0.9 . The ratio of $t_{m c r}$ to $t_{f c r}$ for the specimens that exhibited final rupture was approximately 0.5 . The slope of the $\log \left(\left(d \varepsilon_{c r} / d t\right)_{\min }\right)-\log \left(t_{m c r}\right)$ relationship of a hydrate-sand specimen is almost equal to those of frozen Manchester fine sand ( -0.8 to -1.2$)$ [33] and Fairbanks silt (-1.1) [39]. As shown in Figure 9, $\left(d \varepsilon_{c r} / d t\right)_{\min }$ increased with $\sigma_{c r}{ }^{*}$. The slope of the $\log \left(\left(d \varepsilon_{c r} / d t\right)_{\min }\right)-\log \left(\sigma_{c r}{ }^{*}\right)$ relationship of a hydrate-sand specimen was 9.6, which is nearly equal to that of frozen Manchester fine sand (9.0) [40]. It appears that hydrate sand and frozen sand have many common time-dependent properties.

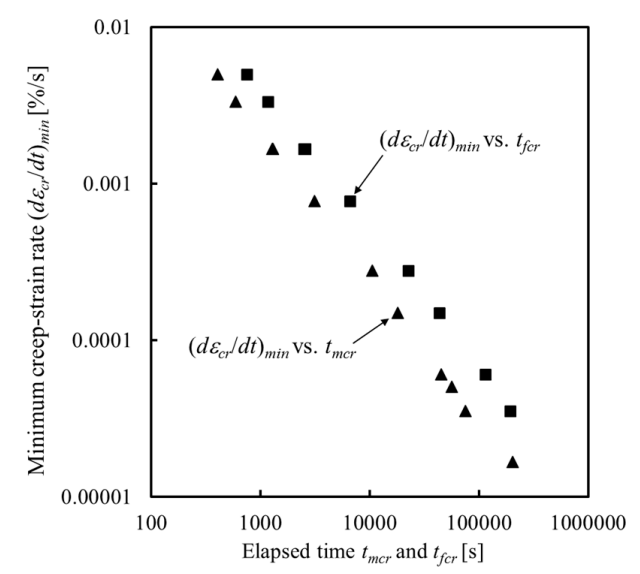

Figure 8. Minimum creep-strain rate $\left(d \varepsilon_{c r} / d t\right)_{\min }$ versus elapsed time until creep-strain rate reached minimum $t_{m c r}$ (triangles) and creep life $t_{f c r}$ (circles).

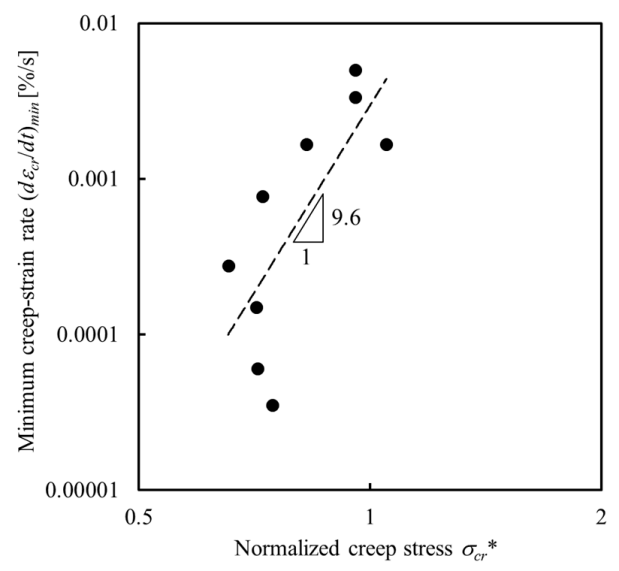

Figure 9. Minimum creep-strain rate $\left(d \varepsilon_{c r} / d t\right)_{\min }$ versus normalized creep stress $\sigma_{c r}{ }^{*}$. 


\section{Discussion}

As reviewed in the previous section, the time-dependence of a hydrate-sand specimen is as strong as that of frozen sand, and is stronger than those of most geomaterials such as rocks and soils [18]. This is supported by the results of constant-strain-rate tests [18,21,23], constant-stress-rate tests [22], and creep tests $[21,22]$ conducted on the hydrate-sand specimens. To date, the relationship between the results of these three tests has been qualitatively described. In this section, the relationship is quantitatively discussed.

\subsection{Differential Stresses Versus Axial Strains in Three Tests}

Figure 10 shows some of the relationships between the loading-rate dependence of strength and the creep behavior. In Figure 10, the following four $\Delta \sigma-\varepsilon_{a}$ relationships are shown: $\sigma_{f e}-\varepsilon_{f e}$ obtained from the constant-strain-rate tests (unfilled triangles), $\sigma_{f_{s}}-\varepsilon_{f_{s}}$ obtained from the constant-stress-rate tests (unfilled squares), and $\sigma_{c r}-\varepsilon_{m c r}$ (filled triangles) and $\sigma_{c r}-\varepsilon_{f c r}$ (filled squares) obtained from the creep tests, where $\varepsilon_{m c r}$ and $\varepsilon_{f c r}$ are the axial strains $\varepsilon_{a}$ corresponding to the minimum creep-strain rate and final rupture, respectively. Although a large variation can be seen in each $\Delta \sigma-\varepsilon_{a}$ relationship, $\Delta \sigma$ appears to be negatively correlated with $\varepsilon_{a}$. For some rocks, it has been reported that both $\varepsilon_{f e}$ and $\sigma_{f e}$ increase with $C_{e}$ and that $\varepsilon_{m c r}$ increases with $\sigma_{c r}[38,41]$. Thus, in this sense, the hydrate-sand specimens exhibited the opposite trend to these rocks. It appears that the $\sigma_{f e}$ versus $\varepsilon_{f e}$ plots are close to the $\sigma_{c r}$ versus $\varepsilon_{m c r}$ plots, and that the $\sigma_{f s}$ versus $\varepsilon_{f_{s}}$ plots are an extension of the $\sigma_{c r}$ versus $\varepsilon_{f c r}$ plots. These quantitative agreements suggest that the creep property of the hydrate-sand specimens is closely related to the loading-rate dependence of strength, which is a typical time-dependent behavior.

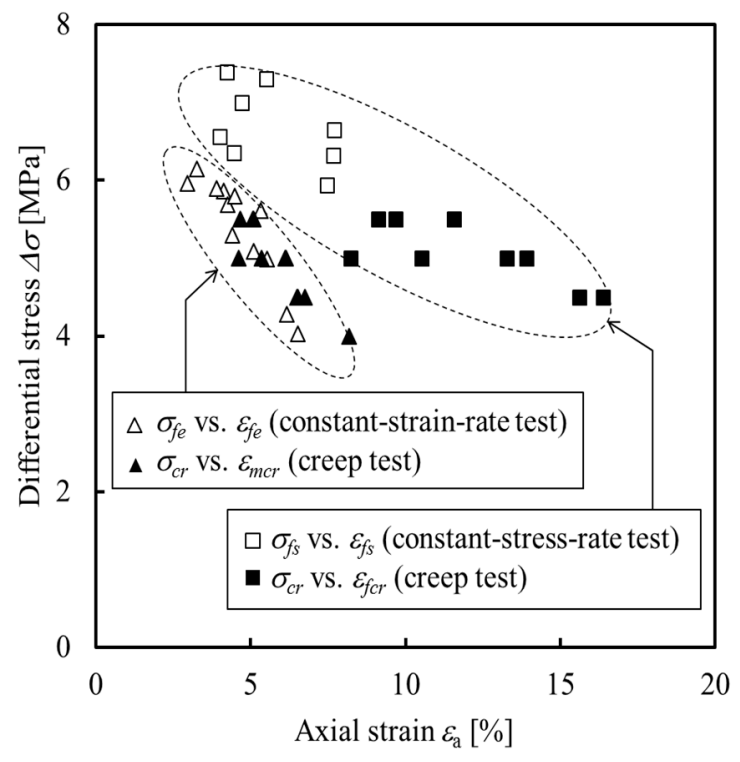

Figure 10. Differential stress $\Delta \sigma$ versus axial strain $\varepsilon_{a}$ at the peak strength in constant-strain-rate tests (unfilled triangles), at the final rupture in constant-stress-rate tests (unfilled squares), at the minimum creep-strain rate in creep tests (filled triangles), and at the final rupture in creep tests (filled squares).

\subsection{Loading-Rate Dependence of Strength}

The normalized strengths $\sigma_{f e}{ }^{*}$ and $\sigma_{f s}{ }^{*}$ and the normalized differential-stress rate $C_{s}{ }^{*}$ are calculated as follows for each hydrate-sand specimen with a different value of $S_{h}$ :

$$
\begin{aligned}
& \sigma_{f e}{ }^{*}=\sigma_{f e} / \sigma_{f e 0.1}, \\
& \sigma_{f s}{ }^{*}=\sigma_{f s} / \sigma_{f e} 0.1,
\end{aligned}
$$




$$
C_{s}^{*}=\sigma_{f e}^{*} /\left(\sigma_{f e} / C_{e}\right), \text { for constant-strain-rate tests, }
$$

or

$$
C_{S}^{*}=C_{s} / \sigma_{f e 0.1} \text {, for constant-stress-rate tests. }
$$

As expressed in Equation (5), $C_{s}{ }^{*}$ for the constant-strain-rate tests is the normalized strength $\sigma_{f e}{ }^{*}$, given by Equation (3), divided by the time to the peak strength $\left(\sigma_{f e} / C_{e}\right)$, which corresponds to the average normalized differential-stress rate (differential-stress rate divided by $\sigma_{f e 0.1}$ ) until the peak strength is reached at the axial-strain rate $C_{e}$. Realignment using the normalized differential stresses given by Equations (3)-(6) made it possible to quantitatively compare the loading-rate dependencies obtained in the constant-strain-rate tests and constant-stress-rate tests. As shown in Figure 11, plots of $\sigma_{f e}{ }^{*}$ and $\sigma_{f_{s}}{ }^{*}$ versus $C_{s}{ }^{*}$ are close to each other. The approximate curves in Figure 11 were calculated using the following expressions obtained by least-squares regression:

$$
\begin{gathered}
\sigma_{f e}^{*}=1.77 \times\left(C_{s}^{*}\right)^{0.0732,} \\
\sigma_{f s}^{*}=1.54 \times\left(C_{s}^{*}\right)^{0.0562} .
\end{gathered}
$$

The determination coefficients of Equations (7) and (8) are 0.86 and 0.87, respectively.

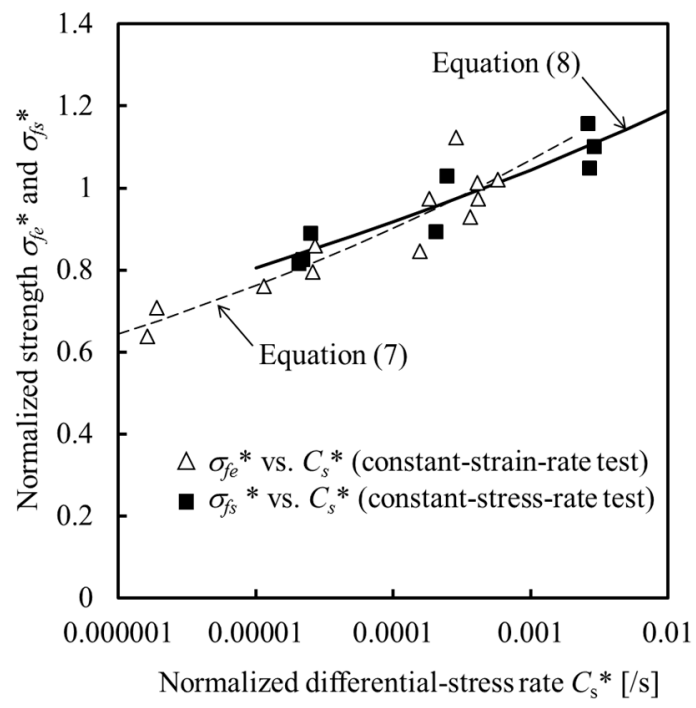

Figure 11. Normalized strengths $\sigma_{f e}{ }^{*}$ and $\sigma_{f s}{ }^{*}$ versus normalized differential-stress rate $C_{s}{ }^{*}$ in constant-strain-rate and constant-stress-rate tests.

\subsection{Creep Life}

Although a large variation can be seen in the relationship between creep life $t_{f c r}$ and normalized creep stress $\sigma_{c r}{ }^{*}$ in Figure 12 [21,22] as is often the case with a geomaterial, $t_{f c r}$ tends to decrease with increasing $\sigma_{c r}{ }^{*}$.

Let us assume that the rupture of a hydrate-sand specimen progresses at a rate proportional to the $n$th power of the normalized differential stress $\sigma^{*}$, where $\sigma^{*}$ is the differential stress divided by $\sigma_{f e 0.1}$ and $n$ is a parameter expressing the time-dependence of a hydrate-sand specimen, and that the final rupture of a specimen occurs when a state quantity $D$ reaches a value $D_{f}$, where $D$ is the time integral of $\left(\sigma^{*}\right)^{n}$ given by

$$
D=\int_{t}\left(\sigma^{*}\right)^{n} d t .
$$

When $\sigma^{*}$ increases with $t$ at a constant rate $C_{S}^{*}$, by substituting

$$
\sigma^{*}=C_{S}^{*} \times t
$$


into Equation (9), we obtain

$$
D=\frac{\left(C_{s}^{*}\right)^{n} \cdot t^{1+n}}{1+n}=\frac{1}{(1+n) \cdot\left(C_{s}^{*}\right)}\left(\sigma^{*}\right)^{1+n}
$$

Considering the moment when final rupture occurs, we obtain

$$
D_{f}=\frac{1}{(1+n) \cdot\left(C_{s}^{*}\right)}\left(\sigma_{f}^{*}\right)^{1+n}
$$

and thus,

$$
\sigma_{f} *=\left\{(1+n) \cdot D_{f} \cdot\left(C_{s}^{*}\right)\right\}^{\frac{1}{1+n}} .
$$

Considering $\sigma_{f e}{ }^{*}$ and $\sigma_{f s}{ }^{*}$ expressed by Equations (7) and (8) as $\sigma_{f}^{*}$ in Equation (13), we obtain $n$ and $D_{f}$. Using Equation (7) derived from the results of the constant-strain-rate tests, we obtain

$$
\begin{aligned}
& n=12.7, \\
& D_{f}=180 .
\end{aligned}
$$

Using Equation (8) derived from the results of the constant-stress-rate tests, we obtain

$$
\begin{aligned}
& n=16.8, \\
& D_{f}=121 .
\end{aligned}
$$

Since $\sigma^{*}$ remains constant at $\sigma_{c r}^{*}$ in the creep tests, by substituting

$$
\sigma^{*}=\sigma_{c r}^{*}
$$

into Equation (9), we obtain

$$
D=\left(\sigma_{c r}^{*}\right)^{n} \times t .
$$

Considering the moment when final rupture occurs, we obtain the following relationship between the normalized creep stress $\sigma_{c r}{ }^{*}$ and creep life $t_{f c r}$ :

$$
D_{f}=\left(\sigma_{c r}^{*}\right)^{n} \times t_{f c r},
$$

and thus,

$$
t_{f c r}=D_{f} \times\left(\sigma_{c r}^{*}\right)^{-n} .
$$

The broken and solid curves in Figure 12 are calculated by substituting Equations (14) and (15) and Equations (16) and (17) into Equation (21), respectively. Although some experimental data are about two orders of magnitude larger than the predictions, the curves do not greatly differ from the plots of $t_{f c r}-\sigma_{c r}{ }^{*}$ on the whole, suggesting that the results of the constant-strain-rate tests, constant-stress-rate tests, and creep tests are in reasonable agreement with the simple hypothesis described above. A lot of tests will be required to verify the hypothesis exactly.

Although creep life is an important characteristic in developing a time-dependent constitutive model, it requires substantial time and effort to obtain the creep life experimentally. In this section, the creep life was found to be reasonably predicted by the loading-rate dependence of strength, which can be obtained with relatively little time and effort. 


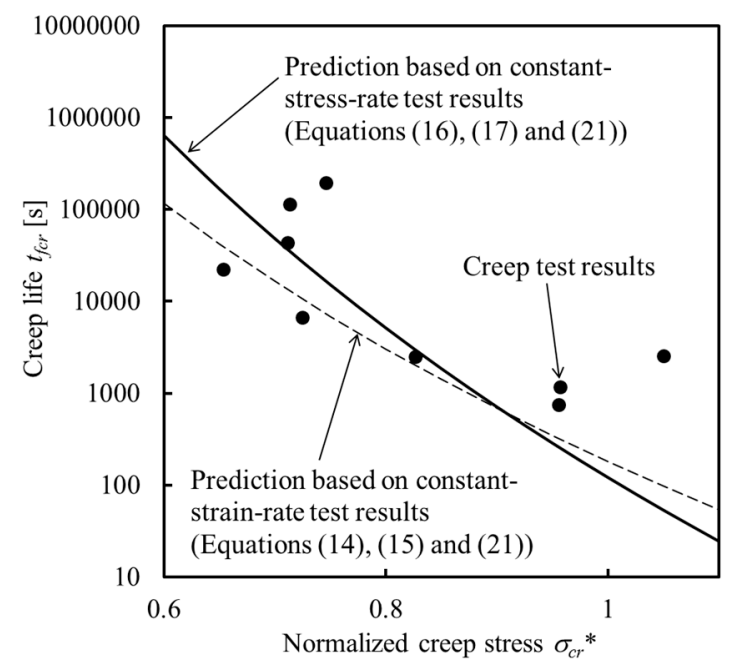

Figure 12. Creep life $t_{f c r}$ versus normalized creep stress $\sigma_{c r}{ }^{*}$ in creep tests.

\subsection{Review of Constitutive Models Proposed for Methane-Hydrate-Bearing Sediments}

The time-dependent properties of methane-hydrate-bearing sediments are important in predicting the long-term geomechanical response to gas extraction over a time scale of decades. When a constitutive model that does not take account of the time-dependent properties of methane-hydrate-bearing sediments is used in a numerical simulation, the long-term deformation of the seabed will be underestimated, because the increase in deformation of the seabed sediments due to the passage of time is ignored.

Many constitutive models for methane-hydrate-bearing sediments have been proposed. Hyodo et al. [28] presented an elastoplastic model for hydrate-bearing soil based on a modified Cam-Clay model [42], which considers the dependence of mechanical properties on pressure and temperature. Klar et al. [11] developed an elastic-perfectly plastic model for hydrate-bearing soil using the results of constant-strain-rate tests at $C_{e}=0.1 \% / \mathrm{min}$ [12]. Uchida et al. [29] developed a constitutive model based on the concept of critical-state soil mechanics, and showed that predictions by their model fitted well with the stress-strain relationships and volumetric behaviors observed in constant-strain-rate tests at $C_{e}=0.1 \% / \mathrm{min}$ for both artificial and natural hydrate-bearing soil [12]. The above-mentioned models are thought to be unable to express the loading-rate dependencies or the creep behaviors without modification, because they do not currently consider the strong time-dependence of hydrate-bearing soil. When these models are improved in the future by incorporating the time-dependent terms (viscous terms) of hydrate-bearing soil into their mathematical equations, the results presented in this and earlier studies [18,21-24,26,27] are expected to be used.

Few constitutive models take account of the time-dependence of hydrate-bearing soil based on experimentally obtained properties. Yoneda et al. [25] presented a visco-elasto-plastic model based on the modified Cam-Clay model [42] and reported that the strong strain-rate dependence of the mechanical properties of hydrate-bearing soil was well predicted by the model. Kimoto et al. [10] also developed an elasto-viscoplastic model with the material parameters determined using the results of triaxial compression tests on natural hydrate-bearing soil. These models seem to be able to express the loading-rate dependencies of hydrate-bearing soil. However, it is not clear whether these models can accurately predict the creep behavior of hydrate-bearing soil $[22,24,26,27]$ and the relationship between the creep property and loading-rate dependence of strength, as shown in Figures 10-12.

Okubo \& Fukui [43] presented a constitutive model to express the time-dependent behaviors of some types of rocks. The model can be applied to various loading conditions such as constant stress rate, constant strain rate, constant stress (creep), and constant strain (stress relaxation). It was developed based on the same hypothesis that was assumed in this study. Thus, the model is thought 
to have the potential to be applicable to the time-dependent behaviors of hydrate-bearing soil. The results presented in this and earlier studies $[18,21-24,26,27]$ are expected to be used in applying the model to hydrate-bearing soil in the future.

\section{Conclusions}

The results of three types of triaxial compression tests-constant-strain-rate test, constant-stress-rate test, and creep test-conducted on hydrate-sand specimens suggested that the time-dependence of methane-hydrate-bearing sediment samples is strong for a geomaterial. The time-dependent properties of the hydrate-sand specimens observed in these tests were quantitatively discussed and found to be almost in agreement with each other. The creep life obtained from the creep tests had a reasonably strong correlation with the loading-rate dependencies of strength obtained from the constant-strain-rate tests and constant-stress-rate tests based on a simple hypothesis describing, using the normalized differential stress, when the final rupture of a hydrate-sand specimen occurs. This suggests that the creep life of a hydrate-sand specimen can be estimated from the loading-rate dependence of strength instead of conducting a creep test, which requires substantial time and effort.

The findings in this study are expected to be used to develop or improve a constitutive equation considering the time-dependent behaviors of hydrate-bearing soil in future studies. Using such a constitutive model that considers the time-dependent property of hydrate-bearing soil will improve the reliability of long-term prediction of the geomechanical response to gas extraction from a reservoir.

Acknowledgments: This work was supported by funding from the Research Consortium for Methane Hydrate Resources in Japan (MH21 Research Consortium) planned by the Ministry of Economy, Trade, and Industry (METI), Japan. We would like to thank Akira Masui, Takao Ohno, and Shigenori Nagase for their help in conducting the experiments.

Author Contributions: Kuniyuki Miyazaki, Norio Tenma and Tsutomu Yamaguchi designed the experiments and interpreted the results; Kuniyuki Miyazaki performed the experiments, analyzed the data and wrote the paper.

Conflicts of Interest: The authors declare no conflicts of interest.

\section{References}

1. Makogon, Y.F. Hydrates of Natural Gas; Pennwell Publishing Co.: Tulsa, OK, USA, 1981.

2. Makogon, Y.F. Perspectives for the Development of Gas-Hydrate Deposits. In Proceedings of the 4th Canadian Permafrost Conference, Calgary, AB, Canada, 2-6 March 1982; pp. 299-304.

3. Kvenvolden, K.A. A Major Reservoir of Carbon in the Shallow Geosphere? Chem. Geol. 1988, 71, 41-51. [CrossRef]

4. Kvenvolden, K.A.; Ginsburg, G.D.; Soloviev, V.A. Worldwide Distribution of Subaquatic Gas Hydrates. Geo-Mar. Lett. 1993, 13, 32-40.

5. Collett, T.S.; Dallimore, S.R. Detailed Analysis of Gas Hydrate Induced Drilling and Production Hazards. In Proceedings of the 4th International Conference on Gas Hydrates, Yokohama, Japan, 19-23 May 2002; pp. 47-52.

6. $\quad$ Bugge, T.; Belderson, R.H.; Kenyon, N.H. The Storegga Slide. Philos. Trans. R. Soc. A 1988, 325, $357-388$. [CrossRef]

7. Kleinberg, R.L. Mechanical Stability of Seafloor Sediments with Application to Gas Hydrate Deposits. In Proceedings of the 5th International Conference on Gas Hydrates, Trondheim, Norway, 13-16 June 2005; pp. 736-748.

8. Sakamoto, Y.; Shimokawara, M.; Ohga, K.; Miyazaki, K.; Tenma, N.; Komai, T.; Aoki, K.; Yamaguchi, T. Field Scale Simulation for Consolidation and Gas Production Behavior during Depressurization Process of Methane Hydrate in Marine Sediments. In Proceedings of the 2008 Offshore Technology Conference, Houston, TX, USA, 5-8 May 2008; OTC19283.

9. Rutqvist, J.; Moridis, G.J.; Grover, T.; Collett, T. Geomechanical Response of Permafrost-Associated Hydrate Deposits to Depressurization-Induced Gas Production. J. Petrol. Sci. Eng. 2009, 67, 1-12. [CrossRef]

10. Kimoto, S.; Oka, F.; Fushita, T. A Chemo-Thermo-Mechanically Coupled Analysis of Ground Deformation Induced by Gas Hydrate Dissociation. Int. J. Mech. Sci. 2010, 52, 365-376. [CrossRef] 
11. Klar, A.; Soga, K.; Ng, M.Y.A. Coupled Deformation-Flow Analysis for Methane Hydrate Extraction. Geotechnique 2010, 60, 765-776. [CrossRef]

12. Masui, A.; Haneda, H.; Ogata, Y.; Aoki, K. Effects of Methane Hydrate Formation on Shear Strength of Synthetic Methane Hydrate Sediments. In Proceedings of the 15th International Offshore and Polar Engineering Conference, Seoul, Korea, 19-24 June 2005; pp. 364-369.

13. Winters, W.J.; Waite, W.F.; Mason, D.H.; Gilbert, L.Y.; Pecher, I.A. Effect of Grain Size and Pore Pressure on Acoustic and Strength Behavior of Sediments Containing Methane Gas Hydrate. In Proceedings of the 5th International Conference on Gas Hydrates, Trondheim, Norway, 13-16 June 2005; pp. 507-516.

14. Hyodo, M.; Nakata, Y.; Yoshimoto, N.; Ebinuma, T. Basic Research on the Mechanical Behavior of Methane Hydrate-Sediments Mixture. Soils Found. 2005, 45, 75-85.

15. Clayton, C.R.I.; Priest, J.A.; Best, A.I. The Effects of Disseminated Methane Hydrate on the Dynamic Stiffness and Damping of a Sand. Geotechnique 2005, 55, 423-434. [CrossRef]

16. Clayton, C.R.I.; Priest, J.A.; Rees, E.V.L. The Effects of Hydrate Cement on the Stiffness of Some Sands. Geotechnique 2010, 60, 435-445. [CrossRef]

17. Miyazaki, K.; Masui, A.; Tenma, N.; Ogata, Y.; Aoki, K.; Yamaguchi, T.; Sakamoto, Y. Study on Mechanical Behavior for Methane Hydrate Sediment Based on Constant Strain-Rate Test and Unloading-Reloading Test Under Triaxial Compression. Int. J. Offshore Polar Eng. 2010, 20, 61-67.

18. Miyazaki, K.; Masui, A.; Aoki, K.; Sakamoto, Y.; Yamaguchi, T.; Okubo, S. Strain-Rate Dependence of Triaxial Compressive Strength of Artificial Methane-Hydrate-Bearing Sediment. Int. J. Offshore Polar Eng. 2010, 20, 256-264.

19. Miyazaki, K.; Masui, A.; Sakamoto, Y.; Aoki, K.; Tenma, N.; Yamaguchi, T. Triaxial Compressive Properties of Artificial Methane-Hydrate-Bearing Sediment. J. Geophys. Res. 2011, 116, B06102. [CrossRef]

20. Miyazaki, K.; Tenma, N.; Aoki, K.; Sakamoto, Y.; Yamaguchi, T. Effects of Confining Pressure on Mechanical Properties of Artificial Methane-Hydrate-Bearing Sediment in Triaxial Compression Test. Int. J. Offshore Polar Eng. 2011, 21, 148-154.

21. Miyazaki, K.; Yamaguchi, T.; Sakamoto, Y.; Aoki, K. Time-Dependent Behaviors of Methane-Hydrate Bearing Sediments in Triaxial Compression Test. Int. J. JCRM 2011, 7, 43-48.

22. Miyazaki, K.; Sakamoto, Y.; Aoki, K.; Tenma, N.; Yamaguchi, T.; Okubo, S. Creep Property of Artificial Methane-Hydrate-Bearing Rock. In Proceedings of the 12th ISRM International Congress on Rock Mechanics, Beijing, China, 18-21 October 2011; pp. 747-750.

23. Miyazaki, K.; Tenma, N.; Sakamoto, Y.; Yamaguchi, T.; Okubo, S. Effects of Methane Hydrate Saturation and Confining Pressure on Strain-Rate Dependence of Artificial Methane-Hydrate-Bearing Sediment in Triaxial Compression Test. Int. J. Offshore Polar Eng. 2012, 22, 90-96.

24. Miyazaki, K.; Endo, Y.; Tenma, N.; Yamaguchi, T. Effects of Particle Size Distribution on Viscoelasticity of Artificial Methane-Hydrate-Bearing Sand. Int. J. Offshore Polar Eng. 2015, 25, 112-119.

25. Yoneda, J.; Hyodo, M.; Nakata, Y.; Yoshimoto, N. Time-Dependent Elasto-Plastic Constitutive Equation for Sedimentary Sands Supported by Methane Hydrate. In Proceedings of the 12th Japan Symposium on Rock Mechanics, Ube, Japan, 2-4 September 2008; pp. 431-436.

26. Miyazaki, K.; Tenma, N.; Endo, Y.; Yamaguchi, T. A Viscoelastic Constitutive Equation for Methane-HydrateBearing Sand. In Proceedings of the 8th Asian Rock Mechanics Symposium (ARMS 8), Sapporo, Japan, 14-16 October 2014.

27. Miyazaki, K.; Endo, Y.; Tenma, N.; Yamaguchi, T. A Nonlinear Viscoelastic Constitutive Equation for Artificial Methane-Hydrate-Bearing Sand under Triaxial Compression. In Proceedings of the 8th International Conference on Gas Hydrates, Beijing, China, 28 July-1 August 2014.

28. Hyodo, M.; Nakata, Y.; Orense, R.; Yoshimoto, N.; Yoneda, J. Elastoplastic Constitutive Equation for Methane Hydrate-Supported Sand in Deep Seabed. In Proceedings of the 14th International Symposium on Plasticity and Its Current Applications, Kona, HA, USA, 3-8 January 2008; pp. 349-351.

29. Uchida, S.; Soga, K.; Yamamoto, K. Critical State Soil Constitutive Model for Methane Hydrate Soil. J. Geophys. Res. 2012, 117, B03209. [CrossRef]

30. Miyazaki, K.; Tenma, N.; Aoki, K.; Yamaguchi, T. A Nonlinear Elastic Model for Triaxial Compressive Properties of Artificial Methane-Hydrate-Bearing Sediment Samples. Energies 2012, 5, 4057-4075. [CrossRef]

31. Parameswaran, V.R. Deformation Behaviour and Strength of Frozen Sand. Can. Geotech. J. 1980, 17, 74-88. [CrossRef] 
32. Ting, J.M.; Martin, R.T. Application of the Andrade Equation to Creep Data for Ice and Frozen Soil. Cold Reg. Sci. Technol. 1979, 1, 29-36. [CrossRef]

33. Ting, J.M. On The Nature of the Minimum Creep Rate-Time Correlation for Soil, Ice, and Frozen Soil. Can. Geotech. J. 1983, 20, 176-182. [CrossRef]

34. Sales, F.H. Creep of Frozen Sands; CRREL Technical Report 190; Army Cold Regions Research and Engineering Laboratory: Hanover, NH, USA, 1968.

35. Sales, F.H.; Haines, D. Creep of Frozen Silt and Clay; CRREL Technical Report 252; Army Cold Regions Research and Engineering Laboratory: Hanover, NH, USA, 1974.

36. Murayama, S.; Michihiro, K.; Sakagami, T. Creep Characteristics of Sands. Soils Found. 1984, 24, 1-15. [CrossRef]

37. Okubo, S.; Nishimatsu, Y.; Fukui, K. Complete Creep Curves under Uniaxial Compression. Int. J. Rock Mech. Min. Sci. Geomech. Abstr. 1991, 28, 77-82. [CrossRef]

38. Fukui, K.; Okubo, S.; Nishimatsu, Y. Complete Creep Curve and Its Implication in Long-Term Stability of Underground Structures. In Proceedings of the Korea-Japan Joint Symposium on Rock Engineering, Seoul, Korea, 18-20 July 1996; pp. 81-87.

39. Zhu, Y.; Carbee, D.L. Creep and Strength Behavior of Frozen Silt in Uniaxial Compression; CRREL Report 87-10; Army Cold Regions Research and Engineering Laboratory: Hanover, NH, USA, 1987.

40. Ting, J.M. Tertiary Creep Model for Frozen Sands. J. Geotech. Eng. 1983, 109, 932-945. [CrossRef]

41. Fujii, Y.; Kiyama, T.; Ishijima, Y.; Kodama, J. Circumferential Strain Behavior during Creep Tests of Brittle Rocks. Int. J. Rock Mech. Min. Sci. 1999, 36, 323-337. [CrossRef]

42. Roscoe, K.H.; Burland, J.B. On the Generalised Stress-Strain Behaviour of 'Wet' Clay. In Engineering Plasticity; Cambridge University Press: Cambridge, UK, 1968; pp. 535-609.

43. Okubo, S.; Fukui, K. An Analytical Investigation of a Variable-Compliance-Type Constitutive Equation. Rock Mech. Rock Eng. 2006, 39, 233-253. [CrossRef]

(C) 2017 by the authors. Licensee MDPI, Basel, Switzerland. This article is an open access article distributed under the terms and conditions of the Creative Commons Attribution (CC BY) license (http:// creativecommons.org/licenses/by/4.0/). 